\title{
Stretching Induces the Rearrangement of the Periodontal Ligament Cells without Altering the Orientation of Oxytalan Fibers Relative to the Cell Axis in Vitro
}

\author{
Sachio Tamaoki ${ }^{1}$, Kazuki Nakashima ${ }^{1}$, Yoshinori Yamauchi ${ }^{1}$, Kaori Yamanouchi ${ }^{1}$, \\ Takahiro Fujita1, Eichi Tsuruga ${ }^{2 *}$, Hiroyuki Ishikawa ${ }^{3}$
}

\author{
${ }^{1}$ Section of Orthodontics, Department of Oral Growth \& Development, Division of Clinical Dentistry, Fukuoka Dental College, Fukuoka, \\ Japan \\ ${ }^{2}$ Department of Radiation Science, Graduate School of Health Sciences, Hirosaki University, Hirosaki, Japan \\ ${ }^{3}$ Fukuoka Dental College, Fukuoka, Japan \\ Email: tama@college.fdcnet.ac.jp, marutang@college.fdcnet.ac.jp,yamauchi@college.fdcnet.ac.jp, reneoo@college.fdcnet.ac.jp, \\ tfujita@college.fdcnet.ac.jp, *tsuru@hirosaki-u.ac.jp, ishiro@college.fdcnet.ac.jp
}

How to cite this paper: Tamaoki, S., Nakashima, K., Yamauchi, Y., Yamanouchi, K., Fujita, T., Tsuruga, E. and Ishikawa, H. (2016) Stretching Induces the Rearrangement of the Periodontal Ligament Cells without Altering the Orientation of Oxytalan Fibers Relative to the Cell Axis in Vitro. Open Journal of Stomatology, 6, 252-260.

http://dx.doi.org/10.4236/ojst.2016.612031

Received: November 4, 2016

Accepted: December 10, 2016

Published: December 13, 2016

Copyright $\odot 2016$ by authors and Scientific Research Publishing Inc. This work is licensed under the Creative Commons Attribution International License (CC BY 4.0).

http://creativecommons.org/licenses/by/4.0/

\section{(c) (i) Open Access}

\begin{abstract}
The periodontal ligament (PDL) contains oxytalan fibers as well as collagen fibers, which helps it to withstand the mechanical stress to which it is constantly exposed. The oxytalan fibers are produced by PDL fibroblasts. However, the arrangement of PDL fibroblasts and the orientation of oxytalan fibers relative to the fibroblast cell axis have not been investigated under the condition of mechanical stress. We hypothesized that such stress would alter the arrangement and orientation of these cells and their oxytalan fibers. The aim of this study was to evaluate the effects of stretching strain on PDL fibroblasts, focusing on the cellular arrangement and orientation of oxytalan fibers relative to the long cell axis in cell/matrix layers by staining the major component of the fibers, fibrillin- 1 . The angle between the long cell axis and the oxytalan fibers was approximately 70 degrees under both non-stretching and stretching conditions. Moreover, stretching induced the rearrangement of the cells. This is the first study to demonstrate that stretching induces the rearrangement of the PDL fibroblasts without altering the angle between the long cell axis and the oxytalan fibers. These results may reflect the orientation of oxytalan fibers in the PDL under the condition of mechanical stress.
\end{abstract}

\section{Keywords}

Oxytalan Fibers, Mechanical Stress, Fibrillin, Microfibrils, Periodontal Ligament 


\section{Introduction}

The periodontal ligament (PDL) contains extracellular matrix components that include elastic system fibers as well as collagens. Elastic system fibers exist in the blood vessels, lung tissue, skin and periodontal tissue [1]. These fibers are composed of two distinct components: microfibrils and tropoelastin. Tropoelastin is a precursor of cross-linked elastin. During the formation of elastic fibers, tropoelastin is deposited on the microfibrils, which act as a template [2]. The human PDL contains pure microfibrils that form bundles known as oxytalan fibers, while all three types of fiber are present in the gingiva [3] [4]. Recently, the biomechanical characteristics of oxytalan fibers in the PDL have been investigated in relation to its response to functional and orthodontic forces [5].

Oxytalan fibers were first identified in the PDL and are thought to support vascular orientation and flow. The oxytalan fibers in the PDL are arranged in a vertically oriented network, which encloses the tooth root [6], and are constantly exposed to mechanical stimulation, including tongue pressure, occlusal force and orthodontic force. It has been reported that the oxytalan fibers in the incisor PDL-where the orthodontic force load is high-are increased in both number and size [7].

Human PDL fibroblasts express fibrillin-1, which is the major component of oxytalan fibers. In our previous PDL fibroblast culture experiments, we showed that oxytalan fibers are formed in cell/matrix layers [8]. As the PDL is constantly exposed to mechanical stress, we previously used a stretching system to examine the appearance of oxytalan fibers in vitro [9] [10]. Functional strain has been shown to induce the coalescence of oxytalan fibers in cultured PDL fibroblasts [9], which condition mimics the situations added an intermitted functional force in vivo. However, the mechanism underlying the regularity of the arrangement of the oxytalan fibers in the PDL has not been revealed. Namely, no studies have examined the angle between the long cell axis and the oxytalan fibers, or have reported whether stretching induces the rearrangement of the PDL fibroblasts. We therefore used our stretching apparatus to analyze the behavior of these cells and the relationship between the long cell axis and extracellularly formed fibrillin-1-positive oxytalan fibers under stretched and non-stretched conditions.

\section{Materials and Methods}

\subsection{Cells and Culture}

Human PDL fibroblasts were purchased from Lonza Walkersville Inc.(Walkersville, MD, USA) and cultured in Dulbecco's modified Eagle Medium (Invitrogen, Grand Island, NY, USA) supplemented with 10\% newborn calf serum (NCS; Invitrogen), 100 units $/ \mathrm{ml}$ penicillin and $100 \mu \mathrm{g} / \mathrm{ml}$ streptomycin (Roche Diagnostics, Mannheim, Germany) at $37^{\circ} \mathrm{C}$ in humidified air containing $5 \% \mathrm{CO}_{2}$. When the outgrowth of the cells reached confluence, they were harvested with $0.025 \%$ trypsin (Invitrogen) in PBS, and transferred to plastic culture dishes at a 1:4 split ratio. PDL fibroblasts from the 3rd to 6th passages were used in this study. 


\subsection{The Mechanical Loading Apparatus and the Cyclic Stretching Conditions}

PDL fibroblasts were stretched using a STB-140 STREX cell stretch system (Strex Co., Osaka, Japan), as described previously [9]. Briefly, cells at a density of $1 \times 10^{5} / \mathrm{ml}$ were transferred to an elastic silicone chamber $(4 \mathrm{ml})$ precoated with $50 \mu \mathrm{g} / \mathrm{ml}$ type I collagen (C8919; Sigma, St Louis, MO, USA) under the same culture condition as above section. After $72 \mathrm{hr}$, when the PDL fibroblasts were found to have reached confluence, the medium was replaced with fresh medium and the cells were subjected to stretching (the first day was set as day 0 ). The amplitude and frequency of stretching were controlled by a programmable microcomputer at $5 \%$ of the original strength and $1 / 60 \mathrm{~Hz}$, respectively, in accordance with the methods of our series of studies, which is close to the thickness of oxytalan fibers in vivo [9] [10] [11]. The amplitude and frequency of stretching of non-stretching group were both zero, respectively.

\subsection{Immunofluorescence}

After 7 days of culturing at $37^{\circ} \mathrm{C}$ in humidified air containing $5 \% \mathrm{CO}_{2}$, the PDL fibroblasts were fixed in ice-cold $4 \%$ paraformaldehyde for $15 \mathrm{~min}$, then washed with PBS. Nonspecific immunoreactivity was blocked with $1 \%$ bovine serum albumin in PBS for 1 $\mathrm{hr}$ at room temperature. The cell layers were then incubated for $2 \mathrm{hr}$ at room temperature with the appropriate primary antibodies (polyclonal rabbit antibody against human fibrillin-1 diluted 1:1000, Elastin Products Co., Owensville, MO, USA). The controls included the use of preimmune normal goat IgG for incubation with the primary antibody. After rinsing in PBS, the cells were incubated for $1 \mathrm{hr}$ at room temperature with Alexa Fluor ${ }^{\circledR}$ 488-labeled donkey anti-rabbit IgG antibody (Invitrogen, Grand Island, NY, USA) diluted to 1:1000 with blocking buffer. After the final washing, the cells were subjected to 4', 6-diamidino-2-phenylindole (DAPI) nuclear staining and cytoplasmic staining with DilC12(3) perchlorate (Enzo Life Science, NY, USA) for 1 minute. They were then observed using a fluorescence microscope (BZ-8100, KEYENCE, Osa$\mathrm{ka}$, Japan). The images were scanned and measurements were performed using the Image J software program (National Institutes of Health, Bethesda, MD, USA).

\subsection{The Evaluation of the Arrangement of PDL Fibroblasts and the Relationships of Their Long Cell Axis to the Oxytalan Fibers}

After performing cytoplasmic and nuclear staining, we selected cells arbitrarily depending on the identifiable influence of overlapping cells and the distinctness of the cell outline or the fibers in microscopic fields to evaluate the arrangement of the cells and the relationship between the long cell axis and the oxytalan fibers. We defined the long cell axis as follows.

First, on the periphery of the nucleus, the two points that were furthest from the center of the nucleus were determined. These two points were then connected by a line that defined the long cell axis. This formed the basal line from the initially selected cell. We then measured the angle between the long axes of the other cells and this basal line. 
We selected three cells for the basal line and 45 cells for the angle measurement from three microscopic fields in both the non-stretched and stretched groups.

Next, we measured the angle formed between the oxytalan fibers and the long axis of each cell. The baseline of the oxytalan fibers was the line that connected the two points of intersection between the oxytalan fiber and the outline of the cytoplasm. We measured the angle between the baseline of the oxytalan fiber and the long cell axis (Figure 1). In all cases, the acute angle was measured. When two oxytalan fibers crossed the cell, we determined the mean angle. We selected 15 cells from three microscopic fields in both the non-stretched and stretched groups.

\subsection{Statistical Methods}

To compare the cellular arrangement in the non-stretched and stretched groups, the homogeneity of variance in the angle between the long axis of the basal line and the other cells was evaluated using the F-test. The differences between the two groups in the angle formed by the baseline of oxytalan fibers and the long cell axis were evaluated using the Mann-Whitney $U$ test. $P$ values of $<0.05$ were considered to indicate statistical significance.

\section{Results}

\subsection{The Staining of the Cytoplasm (Red) and Oxytalan Fibers (Green)}

The appearance of the oxytalan fibers on day 7 was examined under a fluorescence microscope. The immunofluorescence images revealed that fibrillin-1-positive oxytalan fibers coalesced as a result of stretching (Figure 2, green in upper panel). This reflects the coalescence of the functional oxytalan fibers in PDL. Moreover, the fibrillin-1-positive oxytalan fiber bundles were observed to lie across the cells in the stretched and non-stretched preparations (Figure 2, lower panel). The red-stained area indicates the cytoplasm, while the blue-stained areas indicate the nuclei. Control immune serum produced no labeling (not shown).
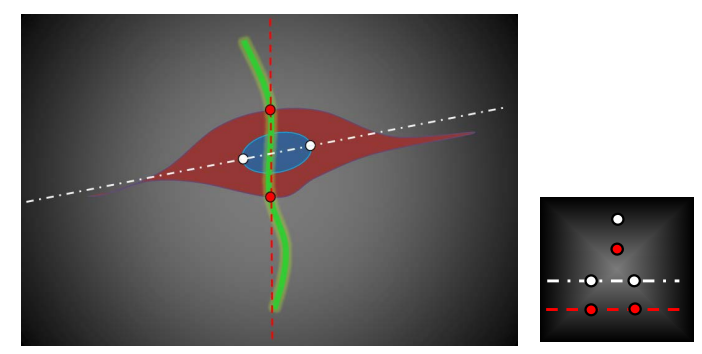

: Apex of nuclei long axis

: Point between cell membrane and oxytalan fiber

: Long-axis of the cell

: Base line of oxytalan fiber

Figure 1. Configuration of the long cell axis and the baseline of the oxytalan fibers. On the perimeter of the nucleus, two points that were located furthest from the center of the nucleus were determined (white points). These two points were then connected by a line that formed the long cell axis (white line). The baseline of oxytalan fibers was then determined (red line) as a straight line that included the two intersection points between the cell membrane and the oxytalan fiber (red point). 


\subsection{The Evaluation of Cellular Arrangement after the Application of Stretching Stress}

We also evaluated the angle formed between the basal line (yellow line in Figure 3) and the long axes of the other cells (white lines in Figure 3). The degree of variation that was observed under non-stretched conditions seemed to be larger than that under stretched conditions. We performed an F-test to confirm the difference in the cellular
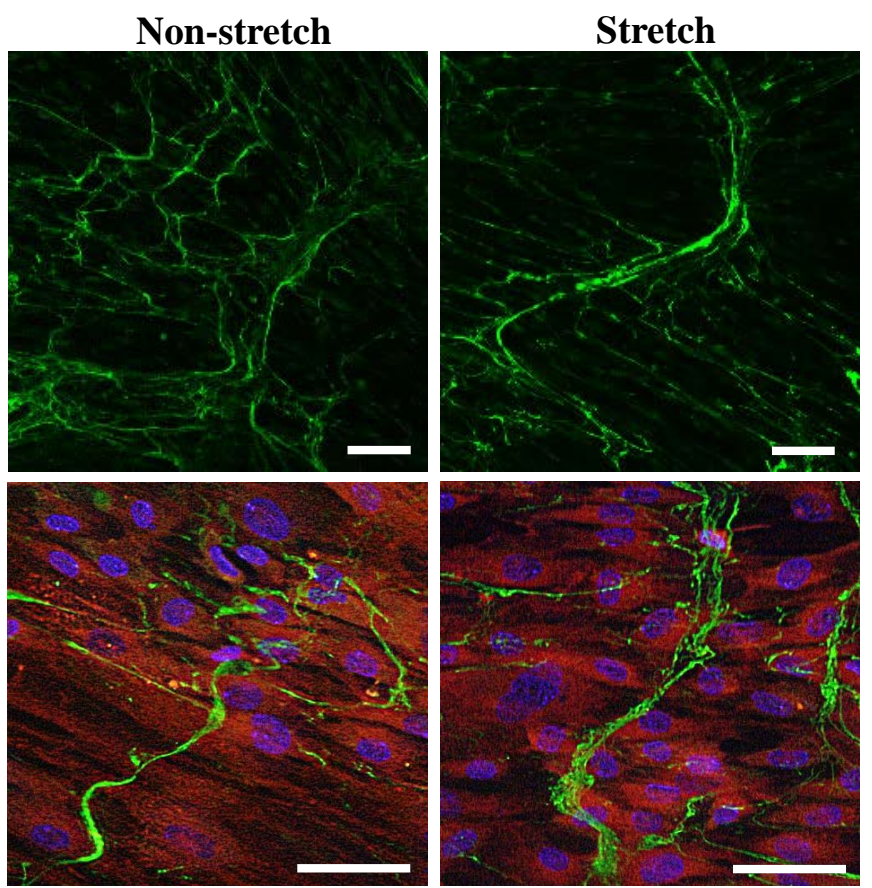

Figure 2. Staining the cytoplasm, oxytalan fibers and nucleus. Red: The cytoplasm of the cell. Green, fibrillin-1-positive oxytalan fibers. Blue, nucleus. The upper panel only contains green, while the lower panel contains all three colors. Scale bar, $50 \mu \mathrm{m}$.

\section{Non-stretch}

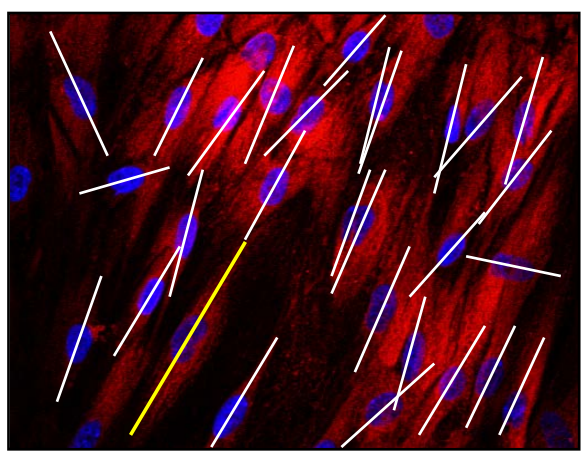

Stretch

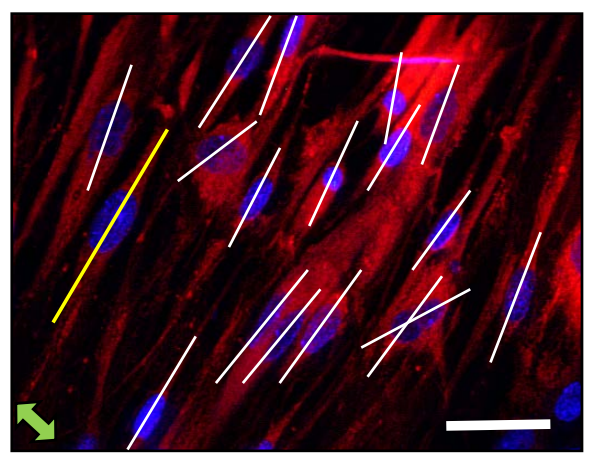

Figure 3. The arrangement of the cells in response to stretching stress. Images for the measurement of the non-stretch and stretch groups. Yellow line, the basal line for the measurement of the long cell axis. White lines, the long axis of the other cells. Green arrow, the direction of stretching. Scale bar, $50 \mu \mathrm{m}$ 
arrangement under non-stretched and stretched conditions. The results demonstrated that the difference between the stretched and non-stretched conditions was statistically significant $(\mathrm{p}<0.01$, Table 1$)$.

\subsection{The Measurement of the Angle between the Cells and Fibers}

We compared the angle formed between the oxytalan fibers and the long cell axis in the stretch and non-stretch groups (Figure 4). In both groups, the mean angle between the long axes of the cells and the oxytalan fibers was approximately 70 degrees. The MannWhitney $U$ test revealed no significant difference between the stretch and non-stretch groups (Table 2).

\section{Discussion}

In the present study we demonstrated that human PDL fibroblasts undergo rearrangement when they are subjected to stretching stress. Moreover, the angle between the long cell axis and the oxytalan fibers across the cell was approximately 70 degrees.

A recent study investigated the arrangement of epithelial cells in response to stretching stress in relation to directional cellular proliferation [12]. In our experiment, the

Table 1. The cellular arrangement in response to stretching stress.

\begin{tabular}{ccc}
\hline & Non-stretch & Stretch \\
\hline Cell number & 28 & 17 \\
variance & 260.20 & 49.77 \\
\hline
\end{tabular}

F test: $\mathrm{p}<0.01$. The angle formed between the long axis of the other cells and the basal line was assessed by the Ftest.

Non-stretch

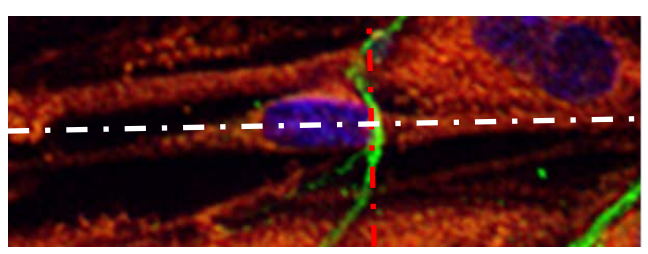

Stretch

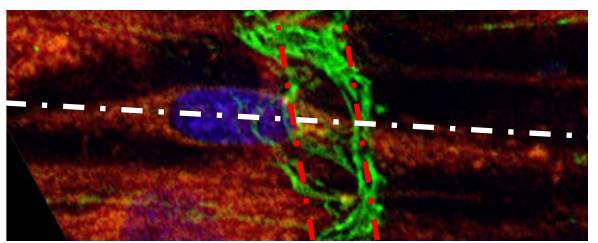

Figure 4. The measurement of the angle between the long cell axis and the oxytalan fibers. Reference images for measurement of the angle between the baseline of the oxytalan fibers and the long cell axis.

Table 2. The difference in angle between the cell and the fiber.

\begin{tabular}{ccc}
\hline & Non-stretch & Stretch \\
\hline Cell number & 15 & 15 \\
Mean & 68.13 & 71.82 \\
SD & 9.90 & 13.83 \\
\hline
\end{tabular}

Mann-Whitney U test: NS, The angle between the baseline of the oxytalan fibers and the long cell axis was assessed in the non-stretched and stretched groups using the Mann-Whitney U test. 
PDL fibroblasts were fully confluent, which meant that randomly directed cells were arranged in response to stretching. This suggests that this form of stress acts on the cytoskeleton though the deposition of integrin (either directly or indirectly) on the cell membrane. Thus, some molecules may play a role in this phenomenon. The oxytalan fibers were shown to lie at roughly a right angle relative to the long cell axis under stretched conditions. The difference, in comparison to non-stretched conditions, did not reach statistical significance.

It is known that the cell surface receptors of the integrin family bind to the Arg-GlyAsp (RGD) cell adhesion region. Fibrillin-1 mediates cell adhesion by binding to the cell surface receptors of the integrin family [13]. Integrin subunits $\alpha \mathrm{v}$ and $\beta 3$ exist in the cell membrane of human PDL fibroblasts [14]. Integrin $\alpha v \beta 3$ binds to synthetic fibrillin-1 RGD peptide. We previously showed that PDL fibroblasts express integrin $\alpha v \beta 3$, which is essential for the formation of fibrillin-1-positive oxytalan fibers in cultured cell/matrix layers [15]. However, the distribution of integrin on the cell surface in this stretching system has not yet been investigated. Further study will be necessary to confirm that the distribution of integrin is unaffected by stretching stress.

We previously demonstrated that functional strain induces the coalescence of oxytalan fibers in cultured PDL fibroblasts. Some molecular interactions control this fiber coalescence. The upregulation of fibulin-5 in response to tension strain may control the formation of microfibril bundles in the PDL [10]. Fibulin-5 of $55 \mathrm{kDa}$ glycoprotein contains RGD motif and can bind to fibrillin-1 [16] [17]. Fibulin-5 is thought to mediate PDL fibroblasts through integrin. Therefore, stretching stress leads rearrangement of fibroblasts, then the distribution of fibulin- 5 consequently may influence arrangement of fibrillin- 1 on the cell surface. Needless to say, main component of the extracellular matrices in PDL is collagen fiber. However, the molecular interaction of type I collagen with components of oxytalan fibers has not been investigated. It should be focused, in future, that how the PDL fibroblasts rearranged by the stretching stress control the orientation of the both fibers in PDL.

Moreover, latent transforming growth factor- $\beta$ binding protein- 2 controls the capacity of fibulin-5 for coalescence [18]. In this study, irrespective of the application of stretching stress, the oxytalan fibers tended were oriented at almost a right angle to the long cell axis. This may reflect the angle of the PDL fibroblasts against the functional oxytalan fibers in PDL. Further study may be necessary to identify other molecules that are involved in the maintenance of PDL homeostasis.

The present study showed that at the cellular level, the angle formed between the long cell axis and the oxytalan fibers in individual cells is constantly maintained at approximately 70 degrees, irrespective of whether the cells are stretched. Moreover, stretching induced the rearrangement of the cells. This may explain the mechanism underlying the regular arrangement of the oxytalan fibers in the functional PDL in vivo.

\section{Acknowledgements}

This study was supported by JSPS KAKENHI Grant Number 25862041 and JP15K- 
11001.

\section{References}

[1] Rosenbloom, J., Abrams, W.R. and Mecham, R. (1993) Extracellular Matrix 4: The Elastic Fiber. The FASEB Journal, 7, 1208-1218.

[2] Mecham, R. and Davis, E. (1994) Extracellular Matrix Assembly and Structure. In: Yurchenco, P., Birk, D. and Mecham, R., Eds., Elastic Fiber Structure and Assembly, Academic Press, New York, 281-314.

[3] Sculean, A., Donos, N., Windisch, P., Reich, E., Gera, I., Brecx, M. and Karring, T. (1999) Presence of Oxytalan Fibers in Human Regenerated Periodontal Ligament. Journal of Clinical Periodontology, 26, 318-321. https://doi.org/10.1034/j.1600-051X.1999.260510.x

[4] Simmons, T. A. and Avery, J. K. (1980) Electron Dense Staining Affinities of Mouse Oxytalan and Elastic Fibers. Journal of Oral Pathology \& Medicine, 9, 183-188. https://doi.org/10.1111/j.1600-0714.1980.tb00376.x

[5] Strydom, H., Maltha, J.C., Kuijpers-Jagtman, A.M. and Von den Hoff, J.W. (2012) The Oxytalan Fibre Network in the Periodontium and Its Possible Mechanical Function. Archives of Oral Biology, 57, 1003-1011. https://doi.org/10.1016/j.archoralbio.2012.06.003

[6] Sims, M.R. (1973) Oxytalan Fiber System of Molars in the Mouse Mandible. Journal of Dental Research, 52, 797-802. https://doi.org/10.1177/00220345730520042501

[7] Sims, M.R. (1976) Reconstitution of the Human Oxytalan System during Orthodontic Tooth Movement. American Journal of Orthodontics, 70, 38-58. https://doi.org/10.1016/0002-9416(76)90259-1

[8] Tsuruga, E., Irie, K. and Yajima, T. (2007) Fibrillin-2 Degradation by Matrix Metalloproteinase-2 in Periodontium. Journal of Dental Research, 86, 352-356. https://doi.org/10.1177/154405910708600410

[9] Tsuruga, E., Nakashima, K., Ishikawa, H., Yajima, T. and Sawa, Y. (2009) Stretching Modulates Oxytalan Fibers in Human Periodontal Ligament Cells. Journal of Periodontal Research, 44, 170-174. https://doi.org/10.1111/j.1600-0765.2008.01099.x

[10] Nakashima, K., Tsuruga, E., Hisanaga, Y., Ishikawa, H. and Sawa, Y. (2009) Stretching Stimulates Fibulin-5 Expression and Controls Microfibril Bundles in Human Periodontal Ligament Cells. Journal of Periodontal Research, 44, 622-627. https://doi.org/10.1111/j.1600-0765.2008.01170.x

[11] Nakashima, K., Tsuruga, E., Nakatomi, Y., Yamauchi, Y., Hata, Y., Tamaoki, S., Sawa, Y. and Ishikawa, H. (2011) Stretch Stimuli Increase Fibulin-5/EMILIN-1 Complex on Oxytalan Fibers in Human Periodontal Ligament Cells. Orthodontic Waves, 70, 15-20. https://doi.org/10.1016/j.odw.2010.09.001

[12] Wyatt, T.P., Harris, A.R., Lam, M., Cheng, Q., Bellis, J. and Dimitracopoulos, A. (2015) Emergence of Homeostatic Epithelial Packing and Stress Dissipation through Divisions Oriented along the Long Cell Axis. Proceedings of the National Academy of Sciences of the United States of America, 112, 5726-5731. https://doi.org/10.1073/pnas.1420585112

[13] Pfaff, M., Reinhardt, D.P., Sakai, L.Y. and Timpl, R. (1996) Cell Adhesion and Integrin Binding to Recombinant Human Fibrillin-1. FEBS Letters, 384, 247-250.

https://doi.org/10.1016/0014-5793(96)00325-0

[14] Bolcato-Bellemin, A.L., Elkaim, R., Abehsera, A., Fausser, J. L., Haikel, Y. and Tenenbaum, H. (2000) Expression of mRNAs Encoding for $\alpha$ and $\beta$ Integrin Subunits, MMPs, and TIMPs in Stretched Human Periodontal Ligament and Gingival Fibroblasts. Journal of 
Dental Research, 79, 1712-1716. https://doi.org/10.1177/00220345000790091201

[15] Tsuruga, E., Sato, A., Ueki, T., Nakashima, K., Nakatomi, Y., Ishikawa, H., Yajima, T. and Sawa, Y. (2009) Integrin $\alpha \mathrm{v} \beta 3$ Regulates Microfibril Assembly in Human Periodontal Ligament Cells. Tissue Cell, 41, 85-89. https://doi.org/10.1016/j.tice.2008.07.005

[16] Nakamura, T., Lozano, P. R., Ikeda, Y., Iwanaga, Y., Hinek, A., Minamisawa, S., Cheng, C. F., Kobuke, K., Dalton, N., Takada, Y., Tashiro, K., Ross Jr., J., Honjo, T. and Chien, K.R. (2002) Fibulin-5/DANCE is Essential for Elastogenesis in Vivo. Nature, 415, 171-175. https://doi.org/10.1038/415171a

[17] Yanagisawa, H., Davis, E.C., Starcher, B.C., Ouchi, T., Yanagisawa, M., Richardson, J.A. and Olson, E.N. (2002) Fibulin-5 Is an Elastin-binding Protein Essential for Elastic Fibre Development in Vivo. Nature, 415, 168-171. https://doi.org/10.1038/415168a

[18] Tsuruga, E., Oka, K., Hatakeyama, Y., Isokawa, K. and Sawa, Y. (2012) Latent Transforming Growth Factor- $\beta$ Binding Protein 2 Negatively Regulates Coalescence of Oxytalan Fibers Induced by Stretching Stress. Connective Tissue Research, 53, 521-527.

https://doi.org/10.3109/03008207.2012.702816

Submit or recommend next manuscript to SCIRP and we will provide best service for you:

Accepting pre-submission inquiries through Email, Facebook, LinkedIn, Twitter, etc.

A wide selection of journals (inclusive of 9 subjects, more than 200 journals)

Providing 24-hour high-quality service

User-friendly online submission system

Fair and swift peer-review system

Efficient typesetting and proofreading procedure

Display of the result of downloads and visits, as well as the number of cited articles

Maximum dissemination of your research work

Submit your manuscript at: http://papersubmission.scirp.org/

Or contact ojst@scirp.org 